\title{
$\square$
}

\section{Controlling for Heterogeneity in Gravity Models of Trade and Integration}

\author{
I-Hui Cheng and Howard J. Wall
}

\begin{abstract}
This paper compares various specifications of the gravity model of trade as nested versions of a general specification that uses bilateral country-pair fixed effects to control for heterogeneity. For each specification, we show that the atheoretical restrictions used to obtain them from the general model are not supported statistically. Because the gravity model has become the "workhorse" baseline model for estimating the effects of international integration, this has important empirical implications. In particular, we show that, unless heterogeneity is accounted for correctly, gravity models can greatly overestimate the effects of integration on the volume of trade.
\end{abstract}

Federal Reserve Bank of St. Louis Review, January/February 2005, 87(1), pp. 49-63.

$\mathrm{n}$ the 1860s, H. Carey first applied

Newtonian physics to the study of human behavior, and the so-called "gravity equation" has since been widely used in the social sciences. In economics, gravity model studies have achieved empirical success in explaining various types of inter-regional and international flows (including labor migration, commuting, customers, hospital patients, and international trade). The gravity model of international trade was developed independently by Tinbergen (1962) and Pöyhönen (1963). In its basic form, the amount of trade between countries is assumed to be increasing in their sizes, as measured by their national incomes, and decreasing in the cost of transportation between them, as measured by the distance between their economic centers. ${ }^{1}$ Following this work, Linnemann (1966) included population as an additional measure of country size, employing what we will call the augmented gravity model. ${ }^{2}$ It has also

\footnotetext{
1 For examples see McCallum (1995), Helliwell (1996), and Boisso and Ferrantino (1997).

${ }^{2}$ For uses of the augmented gravity model, see Oguledo and MacPhee
}

been common to instead specify the augmented model using per capita income, which captures the same effects. ${ }^{3}$ Whichever specification of the augmented model is used, the purpose is to allow for non-homothetic preferences in the importing country and to proxy for the capital/labor ratio in the exporting country (Bergstrand, 1989).

The gravity model of trade has been used widely as a baseline model for estimating the impact of a variety of policy issues, including regional trading groups, currency unions, political blocs, patent rights, and various trade distortions. ${ }^{4}$ Typically, these events and policies are modeled as deviations from the volume of trade predicted by the baseline gravity model and, in the case of regional integration, are captured by dummy vari-

(1994), Boisso and Ferrantino (1997), and Bayoumi and Eichengreen (1997).

3 Examples of the augmented model with per capita income include Sanso, Cuairan, and Sanz (1993), Frankel and Wei (1998), Frankel, Stein, and Wei (1995, 1998), and Eichengreen and Irwin (1998).

4 See Aitken (1973), Brada and Mendez (1983), Bikker (1987), Sanso, Cuairan, and Sanz (1993), McCallum (1995), Helliwell (1996), Frankel (1997), Wei and Frankel (1997), Bayoumi and Eichengreen (1997), Mátyás (1997), Frankel and Wei (1998), Frankel, Stein, and Wei (1998), Smith (1999), and Rose (2000).

I-Hui Cheng is an assistant professor at the National University of Kaohsuing, Taiwan. Howard J. Wall is an assistant vice president at the Federal Reserve Bank of St. Louis. The authors thank Martin Sola, Ron Smith, Jim Dunlevy, and Rob Dittmar for their comments and suggestions. Kristie M. Engemann provided research assistance.

(C) 2005, Federal Reserve Bank of St. Louis. 


\section{Cheng and Wall}

ables. The continuing popularity of the gravity model is highlighted by Eichengreen and Irwin (1998, p. 33), who call it the "workhorse for empirical studies of [regional integration] to the virtual exclusion of other approaches."

The perceived empirical success of the gravity model has come without a great deal of analysis regarding its econometric properties, as its empirical power has usually been stated simply on the basis of goodness of fit (i.e., a relatively high $R^{2}$ ). ${ }^{5}$ The lack of attention paid to the empirical properties of the model is despite the fact that the strength of any baseline model lies in the accuracy of its estimates. Recently, though, several papers have argued that standard cross-sectional methods yield biased results because they do not control for heterogeneous trading relationships. Because of this, these papers introduced fixed effects into the gravity equation. Fixed-effects models allow for unobserved or misspecified factors that simultaneously explain trade volume between two countries and, for example, the probability that the countries will be in the same regional integration regime (Mátyás, 1997; Bayoumi and Eichengreen, 1997; Cheng, 1999; Wall, 2002, 2003; Coughlin and Wall, 2003). ${ }^{6}$ Gravity models with fixed effects have also been used by Glick and Rose (2001) and Pakko and Wall (2001) to estimate the trade effects of currency unions; by Wall (2000) and Millimet and Osang (2004) to estimate the effects of borders on trade; by Egger (2002) to calculate trade potentials; and by Wall (1999) to estimate the costs of protection.

Although the arguments underlying the use of fixed effects as a solution to unobserved heterogeneity are roughly the same in all of these papers, there is little agreement about how to actually specify the fixed effects. For example, Cheng (1999) and Wall (1999) propose two fixed effects for each pair of countries, one for each direction of trade. In Glick and Rose (2001), each pair of

5 See Sanso, Cuairan, and Sanz (1993) for an examination of the predictive power of various specifications of the augmented gravity model. Also, see Oguledo and MacPhee (1994) for a survey of pre1990 empirical results.

${ }^{6}$ Soloaga and Winters (2001) also recognize this problem, but their solution is to estimate yearly gravity models and to calculate the effects of integration as the differences in the predicted trade volumes over time. countries has only one fixed effect. In Mátyás (1997), each country has two fixed effects, one as an exporter and one as an importer. The purpose of this paper is to evaluate the various fixed-effect specifications in terms of the econometric appropriateness of their underlying assumptions. Specifically, we show (i) how the standard pooledcross-section specification and other fixed-effects specifications are special cases of the Cheng (1999) and Wall (1999) specification and (ii) that the restrictions to obtain them cannot be supported empirically. To underscore the importance of getting the fixed-effects specification right, we illustrate how the choice of specification has significant implications when estimating the effects of integration on trade volume.

\section{A STATISTICAL OVERVIEW}

This section briefly sets out the various forms of the gravity model that have been used to estimate bilateral trade flows. These models are restricted versions of a general gravity model, which has a log-linear specification but places no restrictions on the parameters. In the general model, the volume of trade between countries $i$ and $j$ in year $t$ can be characterized by

(1) $\ln X_{i j t}=\alpha_{0}+\alpha_{t}+\alpha_{i j}+\boldsymbol{\beta}_{\mathrm{ijt}}^{\prime} \mathbf{Z}_{\mathrm{ijt}}+\varepsilon_{i j t}, t=1, \ldots, \mathrm{T}$,

where $X_{i j t}$ is exports from country $i$ to country $j$ in year $t$ and $\mathbf{Z}_{\mathrm{ijt}}^{\prime}=\left[z_{i t}, z_{j t} \ldots\right]$ is the $1 \times k$ vector of gravity variables (gross domestic product [GDP], population, and distance). The intercept has three parts: one common to all years and country pairs, $\alpha_{0}$; one specific to year $t$ and common to all pairs, $\alpha_{t}$; and one specific to the country pairs and common to all years, $\alpha_{i j}$. The disturbance term, $\varepsilon_{i j t}$, is assumed to be normally distributed with zero mean and constant variance for all observations. It is also assumed that the disturbances are pairwise uncorrelated.

Obviously, because (1) has only one observation, it is not useful for estimation unless restrictions are imposed on the parameters. The standard single-year cross-section model (CS) imposes the restrictions that the slopes and intercepts are the same across country pairs, that is, $\alpha_{i j}=0$ and $\beta_{\mathrm{ijt}}=\beta_{\mathrm{t}}$, 
(CS) $\ln X_{i j t}=\alpha_{0}+\alpha_{t}+\boldsymbol{\beta}_{\mathrm{t}}^{\prime} \mathbf{Z}_{\mathrm{ijt}}+\varepsilon_{i j t}, t=1, \ldots, \mathrm{T}$,

where $\alpha_{0}$ and $\alpha_{t}$ cannot be separated. Assuming that all the classical disturbance-term assumptions hold, the CS model is estimated by ordinary least squares (OLS) for each year.

The other standard estimation method is a pooled-cross-section model (PCS), which imposes the further restriction on the general model that the parameter vector is the same for all $t, \boldsymbol{\beta}_{1}=\boldsymbol{\beta}_{2}=$ $\ldots=\boldsymbol{\beta}_{\mathrm{T}}=\boldsymbol{\beta}$, although it normally allows the intercepts to differ over time:

(PCS) $\ln X_{i j t}=\alpha_{0}+\alpha_{t}+\boldsymbol{\beta}^{\prime} \mathbf{Z}_{\mathrm{ijt}}+\varepsilon_{i j t}, \quad t=1, \ldots, \mathrm{T}$.

This is estimated by OLS using data for all available years.

Nearly all estimates of the gravity model of trade use either the CS or the PCS model, which, as we show below, both provide biased estimates. To address this bias, we remove the restriction that the country-pair intercept terms equal zero, although we maintain the restriction that the slope coefficients are constant across country pairs and over time. Specifically, we estimate the fixedeffects (FE) model of Cheng (1999) and Wall (1999):

(FE) $\ln X_{i j t}=\alpha_{0}+\alpha_{t}+\alpha_{i j}+\boldsymbol{\beta}^{\prime} \mathrm{Z}_{\mathrm{ijt}}+\varepsilon_{i j t}, t=1, \ldots, \mathrm{T}$.

Note that the country-pair effects are allowed to differ according to the direction of trade (i.e., $\alpha_{i j} \neq$ $\alpha_{j i}$. The FE model is a two-way fixed-effects model in which the independent variables are assumed to be correlated with $\alpha_{i j}$ and is a classical regression model that can be estimated using LSDV (least squares with a dummy variable for each of the country pairs).

As mentioned above, others have proposed alternative fixed-effects models to handle countrypair heterogeneity, each of which can be modeled as a restricted version of the FE model above. The symmetric fixed-effects (SFE) model of Glick and Rose (2001) differs from FE only in that it imposes the restriction that the country-pair effects are symmetric (i.e., $\alpha_{i j}=\alpha_{j i}$ ).

In the Bayoumi and Eichengreen (1997) model, call it DFE, the differences in the dependent and independent variables are used to eliminate the fixed variables, including the country-pair dummies and distance. As with the FE specification, this model allows for the most general fixed effects possible. But rather than estimating the fixed effects using LSDV, it eliminates them by subtracting them out. Specifically,

(DFE) $\Delta \ln X_{i j t}=\gamma_{0}+\gamma_{t}+\boldsymbol{\beta}^{\prime} \Delta \mathbf{Z}_{\mathrm{ijt}}+\mu_{i j t}, \quad t=1, \ldots, \mathrm{T}$,

where $\Delta$ is the difference operator and $\gamma_{0}+\gamma_{t}=$ $\alpha_{t}-\alpha_{t-1}$. In this model the intercept has two parts: $\gamma_{0}$ is the change in the period-specific effect that is common across years and $\gamma_{t}$ is the change that is specific to year $t$.

When there are no time dummies, such a differencing model yields results identical to a model with dummy variables to control for fixed effects. However, with time dummies it is necessary to impose restrictions on the time effects to avoid collinearity, which in turn makes the DFE estimation a restricted form of the FE estimation. If the collinearity restriction is that the first time dummy in the DFE model is equal to zero, this is equivalent to restricting the common component of the change in the period-specific effects as equal to the difference in the first two period-specific effects (i.e., $\gamma_{0}=\alpha_{2}-\alpha_{1}$ ). If, instead, the collinearity restriction is that the sum of the time dummies in the DFE model is zero, this is equivalent to restricting the common component as equal to the difference between the first and last time dummies (i.e., $\gamma_{0}=\alpha_{T}-\alpha_{1}$ ).

Mátyás (1997) proposes

(XFE)

$$
\ln X_{i j t}=\alpha_{0}+\alpha_{t}+\theta_{i}+\omega_{j}+\boldsymbol{\beta}^{\prime} \mathbf{Z}_{\mathrm{ijt}}+\varepsilon_{i j t}, t=1, \ldots, \mathrm{T},
$$

as the correct specification of the gravity model, where the country-specific effect is $\theta_{i}$ when a country is an exporter and is $\omega_{j}$ when it is an importer. Note that in this specification, distance, contiguity, and language are eliminated because they are fixed over time, even though they are not collinear with the country-specific effects. This model is a special case of the FE model in that it has a unique value for each trading pair's intercept, with the restrictions that a country's fixed effect as an exporter or importer is the same for all of its trading partners. This imposes cross-pair restrictions on the intercepts-that is, one of the components of the intercept for Germany-to-Canada trade 
Table 1

Regression Results for Models Using Pooled Data Dependent Variable $=\log$ of Real Exports

\begin{tabular}{|c|c|c|c|c|c|}
\hline & $\begin{array}{c}\text { Pooled } \\
\text { cross-section }\end{array}$ & $\begin{array}{l}\text { Unrestricted } \\
\text { FE model }\end{array}$ & & stricted FE mod & \\
\hline & PCS & $\mathrm{FE}$ & SFE & DFE & XFE \\
\hline Intercept & $6.852 *(0.546)$ & - & - & $0.209 *(0.028)$ & - \\
\hline Origin GDP & $0.617^{*}(0.038)$ & $0.122 *(0.023)$ & $0.213 *(0.025)$ & $0.098 *(0.029)$ & $0.122 *(0.055)$ \\
\hline Destination GDP & $0.511 *(0.035)$ & $0.208 *(0.027)$ & $0.117 *(0.024)$ & $0.258 *(0.029)$ & $0.208^{*}(0.054)$ \\
\hline Origin population & $0.141^{*}(0.038)$ & $-0.390(0.298)$ & $0.935 *(0.268)$ & $-0.482(0.344)$ & $-0.390(0.565)$ \\
\hline Destination population & $0.214 *(0.038)$ & $2.313 *(0.319)$ & $0.989 *(0.268)$ & $1.906 *(0.344)$ & $2.313^{*}(0.584)$ \\
\hline Distance & $-1.025 *(0.023)$ & - & - & - & - \\
\hline Contiguity & $-0.125(0.085)$ & - & - & - & - \\
\hline Common language & $1.075^{*}(0.072)$ & - & - & - & - \\
\hline 1987 & $0.077(0.067)$ & $0.199 *(0.029)$ & $0.199 *(0.038)$ & - & $0.199 *(0.063)$ \\
\hline 1992 & $0.014(0.068)$ & $0.357^{*}(0.043)$ & $0.357^{*}(0.053)$ & $-0.040(0.029)$ & $0.357^{*}(0.093)$ \\
\hline 1997 & $0.051(0.064)$ & $0.482 *(0.058)$ & $0.481 *(0.070)$ & $-0.064 *(0.028)$ & $0.482 *(0.122)$ \\
\hline Observations & 3,188 & 3,188 & 3,188 & 2,391 & 3,188 \\
\hline Parameters & 11 & 804 & 408 & 7 & 63 \\
\hline Log-likelihood & $-5,163.27$ & $-1,663.07$ & $-2,863.46$ & $-1,979.64$ & $-4,704.08$ \\
\hline $\bar{R}^{2}$ & 0.690 & 0.954 & 0.916 & 0.050 & 0.768 \\
\hline
\end{tabular}

NOTE: All non-dummy variables are in logs. White-corrected standard errors are in parentheses; ${ }^{*}$ denotes significance at the 5 percent level. For the DFE model, all variables are in differences from the previous year.

must be the same as one of the components of the intercept for Germany-to-France trade. These restrictions do not change the coefficient estimates very much but, as we show below, lead to biased and rather large residuals, indicating inaccurate in-sample predictions of trade flows.

\section{STANDARD RESULTS}

This section presents regression results for the augmented version of the standard PCS model. ${ }^{7}$ The data set is a balanced panel with 3,188 observations (797 unidirectional country pairs in each of four years: 1982, 1987, 1992, and 1997). ${ }^{8}$ We

7 Because the results for the single-year CS model do not differ substantially from those for the PCS model, we do not present them here. However, they are available upon request.

8 Fixed-effects estimation is sometimes criticized when applied to included observations of non-zero trade between countries listed in all of the relevant World Bank World Development Reports as being uppermiddle or high income during these years. Also, we excluded countries that were identified as highincome oil exporters. The result is a manageable data set that is fairly representative of the literature, which typically includes only OECD members or industrialized countries. Descriptions of the data and their sources are provided in the data appendix.

In the augmented version of the gravity model, the gravity variables are the countries' GDPs, their populations, and the distance between them. Thus, the augmented PCS model assumes that, in a given year, trade flows from exporting country

data pooled over consecutive years on the grounds that dependent and independent variables cannot fully adjust in a single year's time. To avoid this, we left five years between our observations. 


\section{Figure 1}

\section{PCS Residuals by Country Pair}

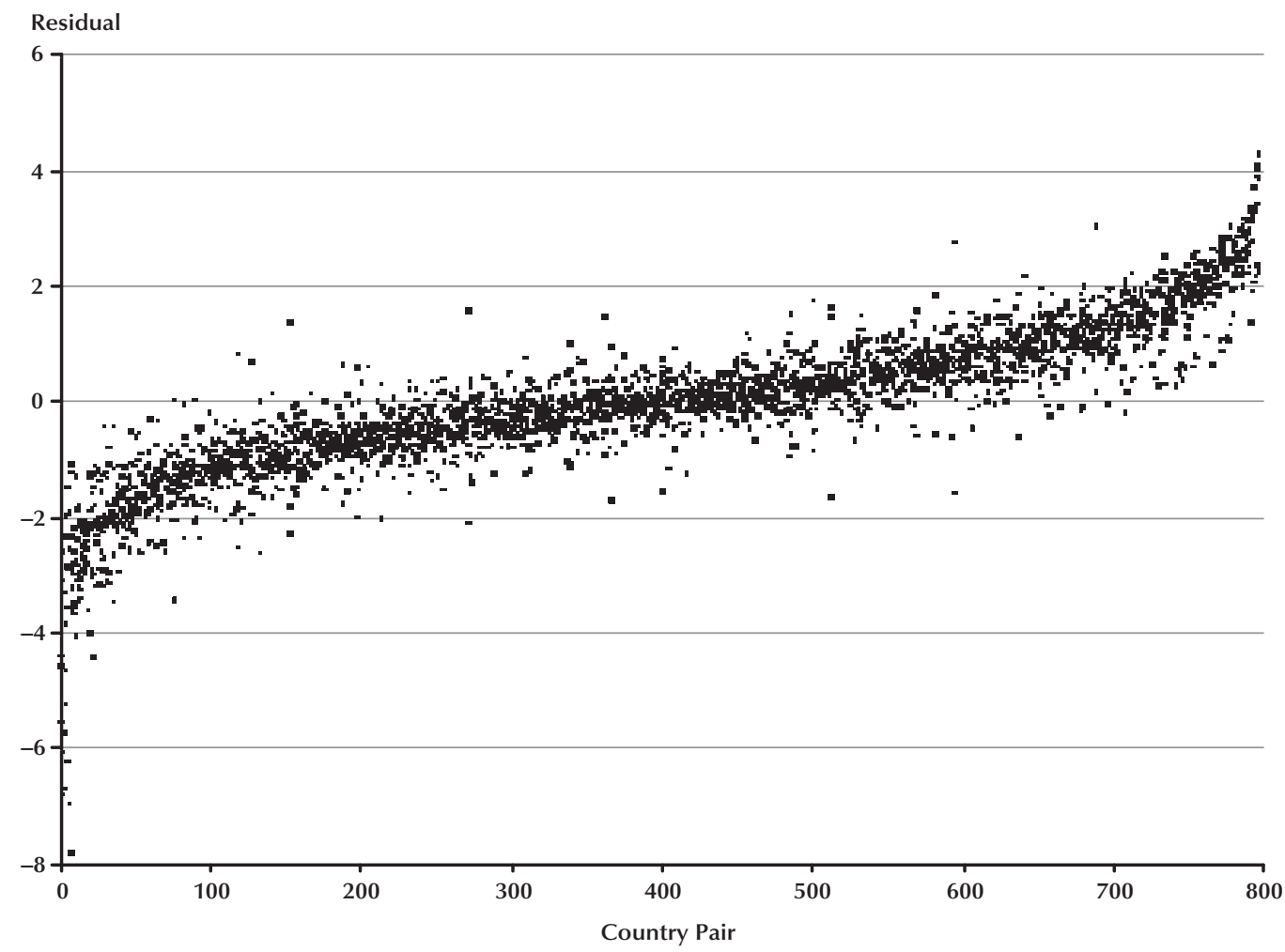

$i$ to importing country $j$ can be estimated using ${ }^{9}$

(2)

$$
\begin{aligned}
& \ln X_{i j t}=\alpha_{0}+\alpha_{t}+\beta_{1} \ln Y_{i t}+\beta_{2} \ln Y_{j t}+\beta_{3} \ln N_{i t} \\
& +\beta_{4} \ln N_{j t}+\delta_{1} \ln D_{i j}+\delta_{2} C_{i j}+\lambda L_{i j}+\varepsilon_{i j t},
\end{aligned}
$$

where $\alpha_{0}$ is the portion of the intercept that is common to all years and trading pairs, $\alpha_{t}$ denotes the year-specific effect common to all trading pairs, $Y_{i}$ and $Y_{j}$ are the two countries' GDPs, $N_{i}$ and $N_{j}$ are their populations, $D_{i j}$ is the distance between them, $C_{i j}$ is a contiguity dummy, and $L_{i j}$ is a common-language dummy. Note that our estimation omits the dummy for 1982 to avoid collinearity.

Because trade flows are expected to be positively related to national incomes, and negatively

${ }^{9}$ Note that the regression could be suitably rearranged to instead obtain the augmented model with per capita income. related to distance, $\beta_{1}, \beta_{2}$, and $\delta_{2}$ are expected to be positive and $\delta_{1}$ is expected to be negative. The signs expected for population coefficients are not as unambiguous, and the literature has not tended to find a consistent sign for $\beta_{3}$ or $\beta_{4} \cdot{ }^{10}$ Because $L_{i j}$ is meant to capture cultural and historical similarities between the trading pairs, which are thought to increase the volume of trade, $\lambda$ is expected to be positive. Finally, we take the time dummies as indicators of the extent of "globalization," which we define as the purported common trend toward greater real trading volumes, independent of the sizes of the economies.

The regression results for PCS are reported in the first column of Table 1 . The signs of the coefficients on distance, common language, and the countries' GDPs are as expected and are statistically significant. Only the negative coefficient on

\footnotetext{
${ }^{10}$ See Oguledo and MacPhee (1994).
} 


\section{Cheng and Wall}

the contiguity dummy of PCS is not as expected, although it is not statistically different from zero. Perhaps surprisingly, the coefficients on the time dummies do not indicate a trend toward globalization.

According to the estimates of the PCS model, (i) an increase in a country's GDP will lead to a less-than-proportional increase in its imports and exports and (ii) a country will export 103 percent more to a market that is half as distant as another otherwise-identical market and 108 percent more to a country with the same first language. Finally, we take the fact that the time dummies are not statistically different from zero to mean that globalization, as defined above, was not an important factor in increasing trade over the period.

Despite the supposed empirical success that we have replicated, there is a severe problem with the standard PCS model. This is clear from Figure 1, which plots the residuals for the PCS model for the 797 unidirectional country pairs in our data set, ordered by the pairs' average residuals. If the PCS estimation were unbiased, there would be no discernable pattern in Figure 1 because the average residual for each country pair would be zero. The residuals for 544 of the country pairs, however, always have the same sign. In other words, the PCS model consistently misestimated the volume of trade for at least 68 percent of the country pairs.

\section{THE GRAVITY MODEL WITH COUNTRY-PAIR FIXED EFFECTS}

\section{The Model}

Standard cross-section estimates of the gravity model yield biased estimates of the volume of bilateral trade because there is no heterogeneity allowed for in the regression equations. With such heterogeneity, a country would export different amounts to two countries, even though the two export markets have the same GDPs and are equidistant from the exporter. This can be because there are historical, cultural, ethnic, political, or geographic factors that affect the level of trade and are correlated with the gravity variables (GDP, population, distance). If so, then estimates that do not account for these factors will suffer from heterogeneity bias.

Some studies using the PCS model have, to some extent, tried to control for this by including things such as whether trading partners share a common language, have had a colonial history, or are in military alliance. However, cultural, historical, and political factors are often difficult to observe, let alone quantify. This is why we control for these factors using a simple fixed-effects model that assumes that there are fixed pair-specific factors that may be correlated with levels of bilateral trade and with the right-hand-side variables. It is in this sense that fixed-effects modeling is a result of ignorance: We do not have a good idea which variables are responsible for the heterogeneity bias, so we simply allow each trading pair to have its own dummy variable.

We assume that the gravity equation for a country pair may have a unique intercept and that it may be different for each direction of trade (i.e., $\alpha_{i j} \neq \alpha_{i j}$ ). However, we retain the assumptions of the PCS model that the slope coefficients are constant over time and across trading pairs. The Cheng (1999) and Wall (1999) specification of the augmented $\mathrm{FE}$ is

(3)

$$
\begin{aligned}
& \ln X_{i j t}=\alpha_{i j}+\alpha_{t}+\beta_{1} \ln Y_{i t}+\beta_{2} \ln Y_{j t}+\beta_{3} \ln N_{i t} \\
& +\beta_{4} \ln N_{j t}+\varepsilon_{i j t},
\end{aligned}
$$

where $\alpha_{i j}$ is the specific "country-pair" effect between the trading partners. The country-pair intercepts include the effects of all omitted variables that are cross-sectionally specific but remain constant over time, such as distance, contiguity, language, and culture. Using the pooled data described above, we have 797 country-pair intercepts.

Because there is a long-standing problem with determining the appropriate measure of economic distance to capture transportation and information costs (see Head and Mayer, 2001, for a review of the issue), an added benefit of the fixed-effects model is that it eliminates the need to include distance in the regression. The most common method for measuring distance is to do as we have done and simply measure it between the centers (often assumed to be the capital cities) of the two 
countries. There are problems with this, such as the implicit assumptions that overland transport costs are the same as those over sea and that all overland/oversea distances are equally costly. To provide just one example, Los Angeles is about $1,300 \mathrm{~km}$ farther from Tokyo than is Moscow, but the economic distance between Tokyo and Los Angeles is certainly much lower than that between Tokyo and Moscow. Our FE approach eliminates the need to include a distance variable, as it controls for all variables that do not change over time.

Another difficulty with standard measures of economic distance is the common assumption that the capital city, or any other single point in the country, is a useful proxy for the economic center. While this may be useful for small countries with one major city, it is wide of the mark for countries like Canada and the United States, which have major cities thousands of miles apart on different oceans and which serve as centers for trade with completely different countries. By using Washington, D.C., or Ottawa to measure distance between the United States or Canada and its Pacific trading partners is to overstate distance by the entire breadth of the North American continent. As the United States has the highest GDP and the highest volume of trade, the mismeasurement of economic distance can bias the estimation of the coefficients on the other variables in the gravity model.

Another advantage of our approach is that it removes the problem of controlling for contiguity. Although it is potentially important, as a great deal of trade can occur from people crossing the border to make everyday purchases, it is accounted for only sometimes. Even when it is accounted for with a dummy variable, as we do above, it still assumes that all contiguity is equivalent and time invariant in terms of its effect on trade. Considering that Canada and the United States, China and Russia, and Argentina and Chile are all equivalently contiguous pairs, this is difficult to abide by.

\section{The Results}

Table 1 reports the estimation results for the augmented version of the FE model. Note that, for comparison with the PCS results, the year dummies are measured relative to that of 1982. Also, the estimates of the country-pair intercepts are omitted for space considerations. According to the results for the FE model, (i) an increase in a country's GDP will lead to a less-than-proportional increase in its imports and exports and (ii) globalization has increased the real volume of trade by 48 percent between 1982 and 1997.

A comparison of the results of the FE and PCS models shows that allowing for trading-pair heterogeneity lowers the estimated income elasticities of trade, greatly increases the absolute value of the coefficients on the countries' populations, and greatly increases the estimated role of globalization. It is obvious from the results that restricting the country-pair effects to zero, as the PCS model does, has statistically significant effects on the results, as is easily confirmed by a likelihood ratio test. ${ }^{11}$ Note also that the residuals from the FE estimation across country pairs (Figure 2) have no discernible pattern.

Therefore, because the PCS model is a restricted form of the FE model and the restrictions are not supported statistically, we conclude that the FE model is the preferred specification of the gravity model. In short, there is no statistical support for imposing the parameter restrictions required by the standard procedures for estimating the gravity model of trade. In the absence of any economic arguments for believing that the intercepts of the gravity equation are the same across trading pairs, we conclude that the FE model is the more appropriate specification.

Oddly, Wei and Frankel (1997, p. 125) reject the inclusion of country-pair dummies a priori on the basis that doing so would undermine their efforts at estimating the effects of variables that are constant over the sample period. Presumably, their worry is that, because these variables are subsumed into the country-pair effects, they are hidden from analysis. This is unfounded because the effects of these variables are easily estimated by regressing them on the country-pair effects from the FE model. Specifically, where the estimates of the 797 country-pair effects are denoted as $\hat{\alpha}_{i j}$, and including the log of distance and the contiguity

${ }^{11}$ This is with $\mathrm{LR}=7,000.4$ and $\chi^{2}(796)=862.75$ at the 5 percent level. 
Figure 2

\section{FE Residuals by Country Pair}

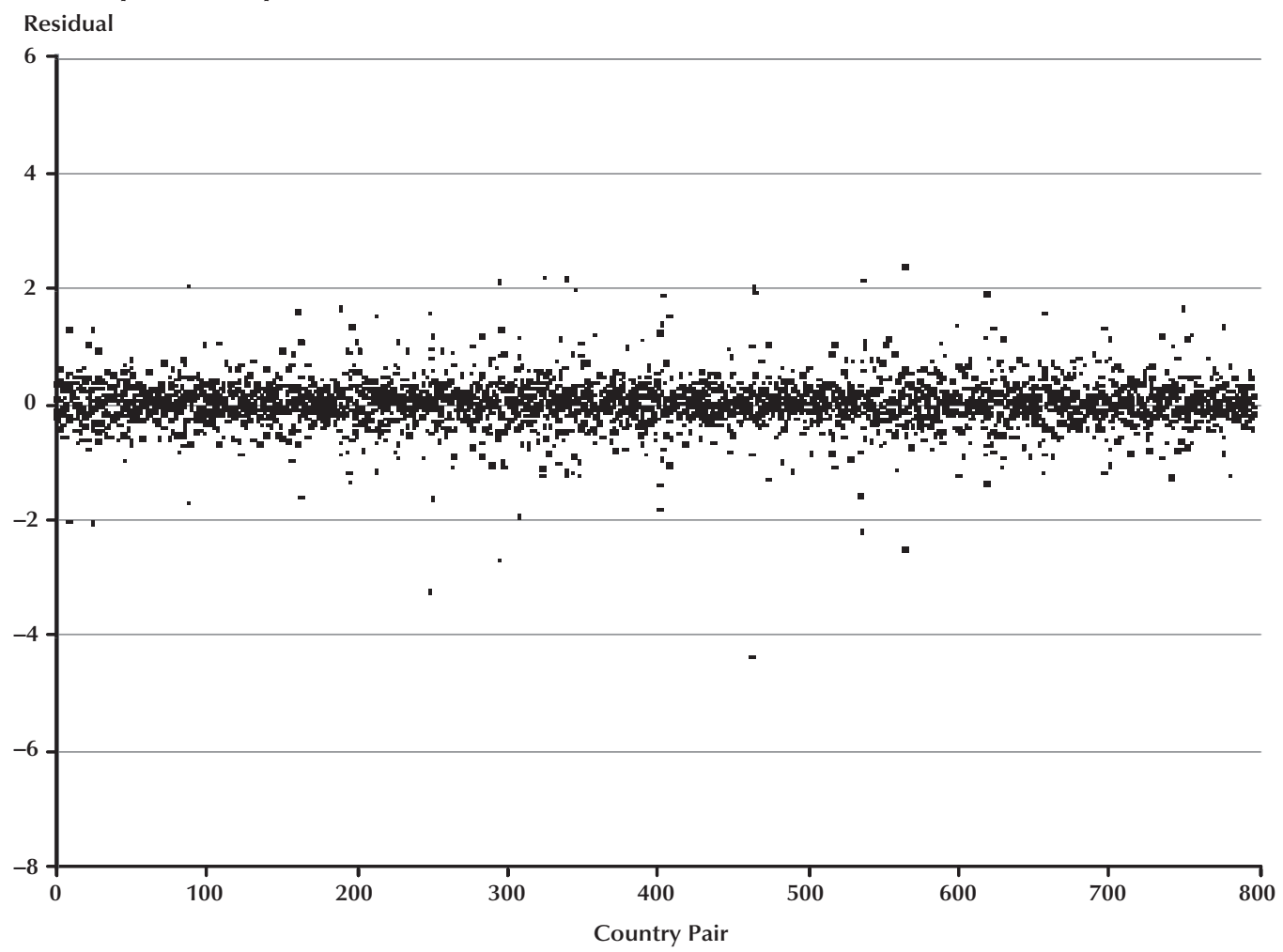

and language dummies as independent variables, we obtain

$$
\hat{\alpha}_{i j}=\underset{(0.405)}{10.408}-1.236 \ln D_{i j}-\underset{(0.049)}{0.746 C_{i j}}+\underset{(0.246)}{1.565 L_{i j}} \text { (0.198) }
$$

The numbers in parentheses are White-corrected standard errors and the $\bar{R}^{2}=0.158$. According to these results, all three variables are statistically significant determinants of the country-pair effects. Inexplicably, though, the coefficient on the contiguity dummy is negative, as in the PCS results. Note that these estimates are quite different from those obtained from the PCS model, in which estimates of the effects of time-invariant factors suffer from the same heterogeneity bias as the time-variant factors. So, far from undermining estimation efforts, it is instead necessary to control for country-pair heterogeneity to obtain unbiased estimates of the importance of time-invariant factors.

\section{ALTERNATIVE FIXED-EFFECTS SPECIFICATIONS}

As discussed earlier, others have used lessgeneral fixed-effects specifications. The first of these, the SFE model of Glick and Rose (2001), is simply (3) with the restriction that $\alpha_{i j}=\alpha_{j i}$. Because our data set does not have the entire set of country pairs for both directions, this does not mean that there are exactly one-half as many country-pair effects as the FE model, although it is close. Our FE estimation had 797 country-pair effects, whereas our SFE estimation has 401. The results of the SFE estimation are in Table 1 and indicate that the symmetry restriction on the country-pair effects has a statistically significant effect on the results. Each of the coefficients on the gravity variables is very different from what we obtain with the FE model, although the coefficients on the year dummies are nearly identical. Also, a likelihood ratio 
test easily rejects the null hypothesis that the restrictions do not have a statistically significant effect on the estimation. ${ }^{12}$ This means that the FE model is preferred statistically to the SFE model.

Taking the time difference of (3), the DFE model of Bayoumi and Eichengreen (1997) is

\section{(4)}

$$
\begin{aligned}
& \Delta \ln X_{i j t}=\gamma_{0}+\gamma_{t}+\beta_{1} \Delta \ln Y_{i t}+\beta_{2} \Delta \ln Y_{j t}+\beta_{3} \Delta \ln N_{i t} \\
& +\beta_{4} \Delta \ln N_{j t}+\mu_{i j t},
\end{aligned}
$$

where the intercept is as defined in the statistical overview, $\gamma_{0}+\gamma_{t}=\alpha_{t}-\alpha_{t-1}$. To prevent collinearity, we set the time dummy for 1987 equal to zero, meaning that other time dummies are measured relative to it. In terms of the more-general FE model, this is equivalent to restricting the common component of the change in the period-specific effects as equal to the difference in the first two period-specific effects (i.e., $\gamma_{0}=\alpha_{2}-\alpha_{1}$ ). ${ }^{13}$ The empirical results are presented in Table 1.

The results for the FE and DFE models are similar in terms of the signs and order of magnitude of the coefficients. Nonetheless, the FE and DFE results differ enough to reject the restrictions needed to obtain the DFE model. This can be confirmed easily by a likelihood ratio test. Therefore, given that the restrictions that DFE imposes on the time dummies are not justified on any economic or statistical grounds, our results indicate that they should not be imposed.

The third alternative to the FE model, XFE, is

(5)

$$
\begin{gathered}
\ln X_{i j t}=\alpha_{0}+\alpha_{t}+\theta_{i}+\omega_{j}+\beta_{1} \ln Y_{i t}+\beta_{2} \ln Y_{j t}+ \\
\beta_{3} \ln N_{i t}+\beta_{4} \ln N_{j t}+\varepsilon_{i j t},
\end{gathered}
$$

where the fixed effect when a country is an exporter is $\theta_{i}$ and when it is an importer is $\omega_{j}$. One way to prevent perfect collinearity in estimating (5) is to impose the restrictions that one of the $\theta$ s and one of the $\omega$ s is zero. Because each $\theta_{i}$ and $\omega_{j}$ comprise part of many $\alpha_{i j}$ s, this is the same as imposing a series of cross-pair restrictions on the

\footnotetext{
12 This is with $\mathrm{LR}=2,400.78$ and $\chi^{2}(395)=442.34$ at the 5 percent level.

${ }^{13}$ The alternative assumption that the sum of the year dummies is zero means that $\gamma_{0}=\alpha_{T}-\alpha_{1}$ and yields the same results except for the time dummies and the constant.
}

$\alpha_{i j}$ s. From the empirical results summarized in the last column of Table 1, it seems that the coefficients are the same as those from the FE model. In fact, the coefficients are not the same, but the differences are so small that they appear only beyond the seventh decimal places provided by STATA. More importantly, though, the standard errors from the XFE model are much larger. Consequently, the FE model is preferred to the $\mathrm{XFE}$ model on the basis of any standard goodness-offit criteria. As with the other restricted fixedeffects specifications, a likelihood ratio test easily rejects the null hypothesis that the arbitrary restrictions imposed by XFE are not statistically benign.

\section{THE EFFECTS OF INTEGRATION}

As we discuss in our introduction, the gravity model has become the primary tool for estimating the effects of regional integration on trade volumes. Up to this point, we have omitted integration variables in order to focus on the importance of controlling for country-pair heterogeneity when estimating gravity models. We now introduce integration into our model and demonstrate the striking effect that heterogeneity bias has on the results. We would also like to alleviate the valid concern that the heterogeneity bias we detected above was due to our implicit assumption that regional integration is uncorrelated with the independent variables.

The most common and straightforward method for estimating the effects of integration in a gravity model is to include dummy variables for each integration regime in place during the sample period (see, for example, Frankel, 1997). Each of these dummies takes the value of 1 for an observation for which the two countries are members of the regime, with the expectation that the coefficients on these dummies are positive. We include five such dummy variables in our model, one each for the European trading bloc, the North American trading bloc, the South American trading bloc (Mercosur), the Australia-New Zealand Closer Economic Relations (CER), and the IsraelUnited States Free Trade Agreement (FTA). 


\section{Cheng and Wall}

Although there has been some deepening of trade integration in the European bloc, the primary change over the period was an expansion in the number of countries covered under the customs union. The formation of the European Community (EC) predates our data set, and Portugal and Spain joined in 1986. The 12 countries of the EC renamed themselves the European Union (EU) in 1992, but this had relatively little effect on internal trade policy, as it was already nearly unfettered under the EC. Expansion of the bloc came in 1994 with the European Economic Area (EEA), which extended the free trade zone to include Austria, Iceland, Finland, Norway, and Sweden. To capture the effect of this trading bloc, our European bloc dummy variable takes the value of 1 when trade is between members of the EC or EU for 1982, 1987, 1992 and when trade is between members of the EEA for 1997.

The Canada-United States Trade Agreement of 1988 established a North American trading bloc that included only Canada and the United States. The North American Free Trade Agreement (NAFTA) expanded the free trade zone in 1994 to include Mexico. We ignore NAFTA's relatively mild deepening of Canada-United States integration and focus on it instead as an extension of the free trade bloc to Mexico. Our North American bloc dummy takes the value of 1 for trade between the United States and Canada for 1992 and between Mexico, Canada, and the United States for 1997.

The third significant trade bloc during the period was Mercosur, which came into force in 1995, reducing trade barriers between Argentina, Brazil, Paraguay, and Uruguay. Our Mercosur dummy takes the value of 1 for trade between any two of these countries in 1997. The AustraliaNew Zealand CER was formed in 1983, so its dummy variable is equal to 1 for trade between the two countries for all years but 1982. Similarly, the Israel-United States FTA entered into force in 1985, so its dummy variable is equal to 1 for trade between the two countries for 1987, 1992, and 1997.

We include these trade bloc dummies in the PCS and FE models and report the empirical results in Table 2. Note that inclusion of these dummies makes little difference for the PCS model. Nonetheless, a likelihood ratio test rejects the null hypotheses that including the trade bloc dummies in the PCS model does not alter the results to a statistically significant extent. ${ }^{14}$ Similarly, the results for the FE model are also not dramatically different when the trade bloc dummies are included, although the null hypothesis that the inclusion of these variables has no statistically significant effect on the results is rejected. ${ }^{15}$

Both models find modest effects on trade from the European trade bloc. The PCS estimates say that the bloc had a statistically insignificant effect, but the FE estimates say that it had a statistically significant effect of 8.2 percent $\left(\mathrm{e}^{0.079}-1=\right.$ 0.082 ). The larger differences between the two models are in the estimated effects of the other trade blocs. The PCS model suggests a 172 percent increase in trade between North American countries because of their trading bloc, whereas the FE model suggests that the bloc led to only a 34 percent increase in trade. For Mercosur, the PCS model estimates an increase in trade of 23 percent that is far from being statistically significant, whereas the FE model estimates a statistically significant effect of 61 percent. The PCS model also estimates the effects of the Australia-New Zealand CER and the Israel-United States FTA as increases in intra-bloc trade of about 300 and 400 percent, respectively. The FE model, however, finds a statistically significant effect of -12 percent for the Australia-New Zealand CER and a statistically insignificant effect of -7.3 percent for the Israel-United States FTA.

These results highlight how allowing for unobserved or unmeasurable heterogeneity can alter gravity model estimates. Specifically, the fact that the estimated effects of the trade blocs change when country-pair heterogeneity is allowed for means that there are pair-specific effects that are correlated with the level of trade between pairs of countries and with the likelihood that the pair

\footnotetext{
${ }^{14}$ This is with $\mathrm{LR}=23.6$ and $\chi^{2}(5)=11.07$ at the 5 percent level.

${ }^{15}$ This is with $\mathrm{LR}=11.9$ and $\chi^{2}(5)=11.07$ at the 5 percent level.
} 


\section{Table 2}

\section{Regression Results with Integration Dummies Dependent Variable $=$ Log of Real Exports}

\begin{tabular}{|c|c|c|c|c|c|}
\hline & \multirow{2}{*}{$\begin{array}{c}\begin{array}{c}\text { Pooled } \\
\text { cross-section }\end{array} \\
\text { PCS }\end{array}$} & \multirow{2}{*}{$\begin{array}{c}\begin{array}{c}\text { Unrestricted } \\
\text { FE model }\end{array} \\
\mathrm{FE}\end{array}$} & \multicolumn{3}{|c|}{ Restricted FE models } \\
\hline & & & SFE & DFE & XFE \\
\hline Intercept & $6.756^{*}(0.581)$ & - & - & $0.208^{*}(0.029)$ & - \\
\hline Origin GDP & $0.618^{*}(0.038)$ & $0.125^{*}(0.023)$ & $0.217^{*}(0.026)$ & $0.098 *(0.029)$ & $0.176 *(0.049)$ \\
\hline Destination GDP & $0.512 *(0.035)$ & $0.212 *(0.028)$ & $0.121 *(0.025)$ & $0.258 *(0.029)$ & $0.263 *(0.050)$ \\
\hline Origin population & $0.138 *(0.039)$ & $-0.316(0.315)$ & $1.009 *(0.297)$ & $-0.476(0.351)$ & $0.884^{\dagger}(0.529)$ \\
\hline Destination population & $0.210 *(0.038)$ & $2.386^{*}(0.339)$ & $1.063 *(0.298)$ & $1.912 *(0.351)$ & $3.575 *(0.561)$ \\
\hline Distance & $-1.013^{*}(0.028)$ & - & - & - & - \\
\hline Contiguity & $-0.145^{\dagger}(0.087)$ & - & - & - & - \\
\hline Common language & $1.050 *(0.073)$ & - & - & - & - \\
\hline European bloc & $0.059(0.062)$ & $0.079^{+}(0.041)$ & $0.079(0.051)$ & $0.021(0.048)$ & $1.196 *(0.059)$ \\
\hline North American bloc & $1.000 *(0.165)$ & $0.294 *(0.140)$ & $0.295^{+}(0.177)$ & $0.204(0.227)$ & $2.675 *(0.216)$ \\
\hline Mercosur & $0.203(0.436)$ & $0.475^{*}(0.172)$ & $0.475^{*}(0.166)$ & $0.365(0.228)$ & $4.133 *(0.246)$ \\
\hline Australia-N.Z. CER & $1.370 *(0.113)$ & $-0.125^{*}(0.044)$ & $-0.124(0.120)$ & $-0.158(0.393)$ & $3.981 *(0.174)$ \\
\hline Israel-U.S. FTA & $1.642 *(0.102)$ & $-0.076(0.296)$ & $-0.076(0.126)$ & $0.024(0.393)$ & $0.426 *(0.168)$ \\
\hline 1987 & $0.067(0.067)$ & $0.189 *(0.031)$ & $0.189 *(0.040)$ & - & $0.020(0.062)$ \\
\hline 1992 & $0.0005(0.069)$ & $0.338 *(0.047)$ & $0.338^{*}(0.058)$ & $-0.040(0.029)$ & $0.027(0.089)$ \\
\hline 1997 & $0.022(0.069)$ & $0.437^{*}(0.069)$ & $0.436 *(0.085)$ & $-0.070 *(0.029)$ & $-0.220^{\dagger}(0.119)$ \\
\hline Observations & 3,188 & 3,188 & 3,188 & 2,391 & 3,188 \\
\hline Parameters & 16 & 809 & 413 & 12 & 68 \\
\hline Log-likelihood & $-5,151.48$ & $-1,657.12$ & $-2,860.65$ & $-1,977.80$ & $-4,427.03$ \\
\hline $\bar{R}^{2}$ & 0.692 & 0.954 & 0.916 & 0.050 & 0.805 \\
\hline
\end{tabular}

NOTE: All non-dummy variables are in logs. White-corrected standard errors are in parentheses; ${ }^{*}$ and + denote significance at the 5 and 10 percent levels, respectively. For the DFE model, all variables are in differences from the previous year.

will enter a trading bloc. ${ }^{16}$ In particular, the lower estimated effect of the Israel-United States FTA using the FE model indicates that there is something special about the relationship between the United States and Israel that makes them trade relatively more with each other than the gravity variables would predict, and which led them to sign a trade agreement. Suppressing this pairspecific effect, as the PCS model does, mistakenly

\footnotetext{
${ }^{16}$ We should note that if we regress the estimated fixed effects from this estimation against distance, contiguity, and language, the results do not differ substantially from those obtained above, which used the estimated fixed effects without controlling for regional integration.
}

suggests that it is the FTA that is responsible for the high trade volume, rather than the special relationship. Similarly, our results suggest for the Australia-New Zealand CER and the North American bloc that the high levels of intra-bloc trade can be attributed to cultural and geographic proximity not completely captured by the language and distance variables, and not primarily to the blocs themselves.

For the sake of comparison, we also estimated the effects of integration using the three alternative fixed-effects specifications. As shown in Table 2, the point estimates of the effects of the blocs on 


\section{Cheng and Wall}

trade are nearly identical between the FE and SFE models. Nonetheless, because the standard errors from the SFE estimates are larger, one would conclude from them that the effects of the European bloc and the Australia-New Zealand CER were statistically no different from zero, even though the FE estimates indicate their statistical significance.

Estimates using the DFE model are also not dramatically different from those using the FE model. Again, though, the larger standard errors mean that the estimated effects are further from standard levels of statistical significance. Indeed, the DFE estimates indicate that none of the trading blocs had a statistically significant effect on trade between members. This occurs because the DFE model imposes restrictions on the time dummies, thereby leading to the misestimation of the effects of regional integration regimes, the expansions of which have a significant trend component.

The XFE model provides estimates of the effects of integration that are dramatically different from those provided by any of the other models. Specifically, it suggests that the European bloc led to an increase in trade of 230 percent, that the North American bloc led to a 1,350 percent increase in trade, and that Mercosur and the Australia-New Zealand CER led to increases in trade of greater than 5,000 percent.

\section{CONCLUSIONS}

The objective of this paper is to compare ways that heterogeneity has been allowed for when using the gravity model to estimate bilateral trade flows. Our empirical analysis shows first that standard pooled-cross-section methods for estimating gravity models of trade suffer from estimation bias due to omitted or misspecified variables. It also shows that the problem is eliminated using the two-way fixed-effects model of Cheng (1999) and Wall (1999) in which country-pair and period dummies are used to reflect the bilateral relationship between trading partners. The fixed effects capture those factors such as physical distance, the length of the border (or contiguity), history, culture, and language that are constant over the span of the data and that are correlated with the volume of bilateral trade.
We show that alternative fixed-effects models proposed by Glick and Rose (2001), Mátyás (1997), and Bayoumi and Eichengreen (1997) are special cases of our model and that the restrictions necessary to obtain these special cases are not supported statistically. Also, because these restrictions have little or no economic support, we argue that they should not be imposed. As the gravity model has become the "workhorse" of empirical studies of the effects of integration, we also compare the various specifications in this regard. We conclude that the country-pair fixed-effects model is preferred statistically to all other specifications and show that estimates of the effects of integration on trade can differ a great deal across the specifications.

\section{REFERENCES}

Aitken, Norman D. "The Effect of the EEC and EFTA on European Trade: A Temporal Cross-Section Analysis." American Economic Review, December 1973, 63(5), pp. 881-92.

Bayoumi, Tamim and Eichengreen, Barry. "Is Regionalism Simply a Diversion? Evidence from the Evolution of the EC and EFTA," in Takatoshi Ito and Anne O. Krueger, eds., Regionalism versus Multilateral Trade Arrangements. Chicago: University of Chicago Press, 1997, pp. 141-64.

Bergstrand, Jeffrey H. “The Generalized Gravity Equation, Monopolistic Competition, and the FactorProportions Theory in International Trade." Review of Economics and Statistics, February 1989, 71(1), pp. 143-53.

Bikker, Jacob A. “An International Trade Flow Model with Substitution: An Extension of the Gravity Model.” Kyklos, 1987, 40(3), pp. 315-37.

Boisso, Dale and Ferrantino, Michael. "Economic Distance, Cultural Distance, and Openness in International Trade: Empirical Puzzles." Journal of Economic Integration, December 1997, 12(4), pp. 456-84.

Brada, Josef C. and Mendez, Jose A. "Regional Economic Integration and the Volume of IntraRegional Trade: A Comparison of Developed and 
Developing Country Experience.” Kyklos, 1983, 36(4), pp. 589-603.

Cheng, I-Hui. "The Political Economy of Economic Integration.” Ph.D. Dissertation, Birkbeck College, University of London, July 1999.

Coughlin, Cletus C. and Wall, Howard J. "NAFTA and the Changing Pattern of State Exports." Papers in Regional Science, October 2003, 82(4), pp. 427-50.

Egger, Peter. "An Econometric View on the Estimation of Gravity Models and the Calculation of Trade Potentials." The World Economy, February 2002, 25(2), pp. 297-312.

Eichengreen, Barry and Irwin, Douglas A. "The Role of History in Bilateral Trade Flows," in Jeffrey A. Frankel, ed., The Regionalization of the World Economy. Chicago: University of Chicago Press, 1998, pp. 33-57.

Feenstra, Robert C. "World Trade Flows, 1980-1997." Center for International Data, University of California, Davis, March 2000.

Frankel, Jeffrey A. Regional Trading Blocs in the World Economic System. Washington, DC: Institute for International Economics, 1997.

Frankel, Jeffrey; Stein, Ernesto and Wei, Shang-Jin. "Trading Blocs and the Americas: The Natural, the Unnatural, and the Super-Natural." Journal of Development Economics, June 1995, 47(1), pp. 61-95.

Frankel, Jeffrey A.; Stein, Ernesto and Wei, Shang-Jin. "Continental Trading Blocs: Are They Natural and Supernatural?” in Jeffrey A. Frankel, ed., The Regionalization of the World Economy. Chicago: University of Chicago Press, 1998, pp. 91-113.

Frankel, Jeffrey A. and Wei, Shang-Jin. "Regionalization of World Trade and Currencies: Economics and Politics," in Jeffrey A. Frankel, ed., The Regionalization of the World Economy. Chicago: University of Chicago Press, 1998, pp. 189-219.

Glick, Reuven and Rose, Andrew K. "Does a Currency Union Affect Trade? The Time Series Evidence.” NBER Working Paper No. 8396, National Bureau of Economic Research, July 2001.
Head, Keith and Mayer, Thierry. "Illusory Border Effects: How Far Is an Economy from Itself?" Working Paper, University of British Columbia, 2001.

Helliwell, John F. "Do National Borders Matter for Quebec's Trade?” Canadian Journal of Economics, August 1996, 29(3), pp. 507-22.

Linnemann, Hans. An Econometric Study of International Trade Flows. Amsterdam: NorthHolland, 1966.

McCallum, John. "National Borders Matter: CanadaU.S. Regional Trade Patterns.” American Economic Review, June 1995, 85(3), pp. 615-23.

Mátyás, László. "Proper Econometric Specification of the Gravity Model.” The World Economy, May 1997, 20(3), pp. 363-68.

Millimet, Daniel L. and Osang, Thomas. "Do State Borders Matter for U.S. Intranational Trade? The Role of History and Internal Migration.” Working Paper, Southern Methodist University, May 2004.

Oguledo, Victor Iwuagwu and MacPhee, Craig R. "Gravity Models: A Reformulation and an Application to Discriminatory Trade Arrangements." Applied Economics, February 1994, 26(2), pp. 10720.

Pakko, Michael R. and Wall, Howard J. "Reconsidering the Trade-Creating Effects of a Currency Union." Federal Reserve Bank of St. Louis Review, September/October 2001, 83(5), pp. 37-45.

Pöyhönen, P. “A Tentative Model for the Volume of Trade Between Countries." Weltwirtschaftliches Archiv, 1963, 90(1), pp. 93-100.

Rose, Andrew K. “One Money, One Market: The Effect of Common Currencies on Trade." Economic Policy: A European Forum, April 2000, 15(30), pp. 7-33.

Sanso, Marcos; Cuairan, Rogelio and Sanz, Fernando. "Bilateral Trade Flows, the Gravity Equation, and Functional Form." Review of Economics and Statistics, May 1993, 75(2), pp. 266-75. 


\section{Cheng and Wall}

Smith, Pamela J. “Are Weak Patent Rights a Barrier to U.S. Exports?” Journal of International Economics, June 1999, 48(1), pp. 151-77.

Soloaga, Isidro and Winters, L. Alan. "Regionalism in the Nineties: What Effect on Trade?" The North American Journal of Economics and Finance, March 2001, 12(1), pp. 1-29.

Tinbergen, Jan. Shaping the World Economy: Suggestions for an International Economic Policy. New York: The Twentieth Century Fund, 1962.

Wall, Howard J. "Using the Gravity Model to Estimate the Costs of Protection." Federal Reserve Bank of St. Louis Review, January/February 1999, 81(1), pp. 33-40.

Wall, Howard J. "Gravity Model Specification and the Effect of the Canada-U.S. Border." Working Paper No. 2000-024A, Federal Reserve Bank of St. Louis, September 2000.

Wall, Howard J. "Has Japan Been Left Out in the Cold by Regional Integration?” Bank of Japan, Monetary and Economic Studies, April 2002, 20(2), pp. 117-34.

Wall, Howard J. "NAFTA and the Geography of North American Trade." Federal Reserve Bank of St. Louis Review, March/April 2003, 85(2), pp. 13-26.

Wei, Shang-Jin and Frankel, Jeffrey A. "Open versus Closed Trading Blocs,” in Takatoshi Ito and Anne O. Krueger, eds., Regionalism versus Multilateral Trade Arrangements. Chicago: University of Chicago Press, 1997, pp. 119-39. 


\section{DATA APPENDIX}

\section{DEFINITIONS OF VARIABLES}

Real Exports, measured in millions of U.S. dollars, from World Trade Flows, 1980-1997 (see Feenstra, 2000). Deflated using CPI-U-RS from the Bureau of Labor Statistics.

Real Gross Domestic Product is in millions of U.S. dollars at market prices from the World Bank's World Development Indicators 1999 CD-ROM. Deflated using CPI-U-RS from the Bureau of Labor Statistics.

Population in thousands of inhabitants from the World Bank's World Development Indicators 1999 CD-ROM.

Distance, expressed in kilometers, is the great circle distance between geographic centers, using the Haversine formula. Coordinates from the CIA's The World Factbook 2000.

Contiguity is equal to 1 if two trading partners share a border. From the CIA's The World Factbook 2000.

Common Language is equal to 1 if two trading partners share a common first language. From the CIA's The World Factbook 2000.

European Bloc is equal to 1 when both countries are members of the EC for 1982 or 1987, the EU for 1992, or the EEA for 1997.

North American Bloc is equal to 1 for Canada-United States trade for 1992 and 1997, and for Canada-Mexico and United States-Mexico trade for 1997.

Mercosur is equal to 1 in 1997 for trade between Argentina, Brazil, Paraguay, and Uruguay.

Australia-New Zealand CER is equal to 1 in 1987, 1992, and 1997 for trade between Australia and New Zealand.

Israel-United States FTA is equal to 1 in 1987, 1992, and 1997 for trade between Israel and the United States.

\section{THE 29 COUNTRIES INCLUDED IN THE DATA SET}

Argentina, Australia, Austria, Belgium-Luxembourg, Brazil, Canada, Denmark, Finland, France, Germany, Greece, Hong Kong, Ireland, Israel, Italy, Japan, South Korea, Mexico, the Netherlands, New Zealand, Norway, Portugal, Singapore, Spain, Sweden, Switzerland, the United Kingdom, Uruguay, and the United States. 
